\title{
Clean Your Hands 5th May 2017: 'Fight antibiotic resistance - it's in your hands'
}

\section{Ermira Tartari ${ }^{1,2}$, Daniela Pires ${ }^{1,3}$ and Didier Pittet ${ }^{1 *}$}

Preventing healthcare-associated infections and reducing their avoidable impact on health systems is critical today to make facilities safer for patients worldwide [1]. In addition, the increasing public health burden of antimicrobial resistance (AMR) urges to action [2]. Stronger political commitment in reducing AMR was highlighted at the last United Nations General Assembly in September 2016 in New York.

Hand hygiene is at the center of effective infection prevention and control (IPC) to combat AMR spread [3]. The World Health Organization (WHO) recently issued guidelines on the Core Components of effective IPC programmes [1]. Their implementation will allow for strong, resilient health systems in all settings. The guidelines include the application of a multimodal strategy that consists in achieving system change (infrastructure and resources), raising awareness, education and training, monitoring and timely feedback and a patient safety culture that includes visibly committed leadership. This approach improves hand hygiene, reduces infections and saves lives [4]. Therefore, on the occasion of the upcoming $5^{\text {th }}$ May 2017 Global Annual Hand Hygiene Day, WHO urges policy makers, top-level managers, IPC specialists and other health professionals to focus on the fight against AMR spread, by building ever stronger hand hygiene and IPC programmes (Table 1).

We encourage health facilities worldwide to endorse the WHO's $5^{\text {th }}$ May 2017 campaign [5] and further improve hand hygiene, fight antibiotic resistance and commit to progressing towards adherence with all core components of IPC programmes.
Table $15^{\text {th }}$ May 2017 key World Health Organization campaign messages

Health workers: "Clean your hands at the right times and stop the spread of antibiotic resistance."

Hospital Chief Executive Officers and Administrators: "Lead a year-round infection prevention and control programme to protect your patients from resistant infections."

Policy-makers: "Stop antibiotic resistance spread by making infection prevention and hand hygiene a national policy priority."

IPC leaders: "Implement WHO's Core Components for infection prevention, including hand hygiene, to combat antibiotic resistance."

Let's fight antibiotic resistance together; it's in our hands.

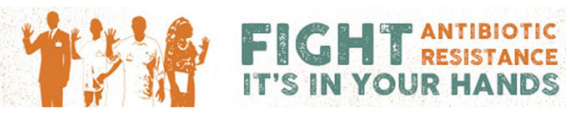

\begin{abstract}
Abbreviations
AMR: Antimicrobial resistance; IPC: Infection prevention and control; WHO: World Health Organization.
\end{abstract}

\section{Acknowledgments}

We thank Mohamed Abbas, Geneva, Switzerland who provided helpful input.

\section{Funding}

Ermira Tartari and Daniela Pires are partially supported by the Swiss National Science Foundation (32003B_163262) for hand hygiene research activities. Daniela Pires is also supported by Fundação para a Ciência e a Tecnologia (SFRH/SINT/95317/2013).

\section{Availability of data and materials}

Not applicable.

\section{Authors' contributions \\ DP made contributions to the conception, the design and reviewing the manuscript. ET and DP drafted the commentary. All authors read and approved the final manuscript.}

\footnotetext{
* Correspondence: didier.pittet@hcuge.ch

'Infection Control Programme and WHO Collaborating Centre on Patient

Safety - Infection Control \& Improving Practices, University of Geneva

Hospitals and Faculty of Medicine, 4 Rue Gabrielle-Perret-Gentil, 1211

Geneva, Switzerland

Full list of author information is available at the end of the article
}

Competing interests

The authors decalre that they have no competing interests.

\section{Consent for publication}

Not applicable. 


\section{Ethics approval and consent to participate}

No patient-related data were collected. Ethical approval was therefore not required.

\section{Publisher's Note}

Springer Nature remains neutral with regard to jurisdictional claims in published maps and institutional affiliations.

\section{Author details}

${ }^{1}$ Infection Control Programme and WHO Collaborating Centre on Patient Safety - Infection Control \& Improving Practices, University of Geneva Hospitals and Faculty of Medicine, 4 Rue Gabrielle-Perret-Gentil, 1211 Geneva, Switzerland. ${ }^{2}$ Infection Control Unit, Mater Dei Hospital, Msida, Malta. ${ }^{3}$ Department of Infectious Diseases, Centro Hospitalar Lisboa Norte and Faculdade de Medicina da Universidade de Lisboa, Lisbon, Portugal.

\section{Received: 6 April 2017 Accepted: 7 April 2017}

\section{Published online: 05 May 2017}

\section{References}

1. World Health Organization. Guidelines on core components of infection prevention and control programmes at the national and acute health care facility level. 2016. Available at: http://apps.who.int/iris/handle/10665/ 251730. Accessed 30 January 2017

2. World Health Organization. Global action plan on antimicrobial resistance. 2015. Available at: http://apps.who.int/iris/handle/10665/193736. Accessed 30 January 2017.

3. World Health Organization. WHO guidelines on hand hygiene in health care: first global patient safety challenge: clean care is safer care. Geneva, Switzerland. 2009. Available at: http://apps.who.int/iris/bitstream/10665/ 44102/1/9789241597906_eng.pdf. Accessed 30 January 2017.

4. Luangasanatip N, Hongsuwan M, Limmathurotsakul D, et al. Comparative efficacy of interventions to promote hand hygiene in hospital: systematic review and network meta-analysis. BMJ. 2015;351:h3728.

5. World Health Organization. SAVE LIVES: Clean Your Hands WHO's Global Annual Campaign Advocacy Toolkit. Available at: http:/www.who.int/gpsc/ 5may_advocacy-toolkit.pdf?ua=1. Accessed 30 January 2017.

\section{Submit your next manuscript to BioMed Central} and we will help you at every step:

- We accept pre-submission inquiries

- Our selector tool helps you to find the most relevant journal

- We provide round the clock customer support

- Convenient online submission

- Thorough peer review

- Inclusion in PubMed and all major indexing services

- Maximum visibility for your research

Submit your manuscript at www.biomedcentral.com/submit
Biomed Central 